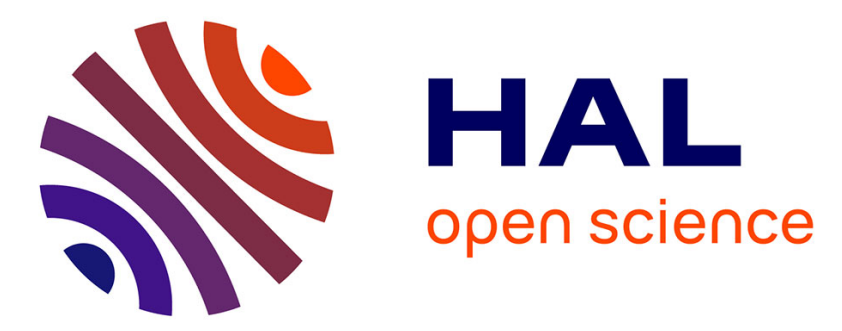

\title{
Effects of temperature on the mechanical behavior of filled and unfilled silicone rubbers
}

Thierry Rey, Grégory Chagnon, Jean-Benoit Le Cam, Denis Favier

\section{To cite this version:}

Thierry Rey, Grégory Chagnon, Jean-Benoit Le Cam, Denis Favier. Effects of temperature on the mechanical behavior of filled and unfilled silicone rubbers. 8th European Conference on Constitutive Models for Rubbers, Jun 2013, San Sebastian, Spain. pp.511-514. hal-00936536

\section{HAL Id: hal-00936536 https://hal.science/hal-00936536}

Submitted on 30 Jan 2014

HAL is a multi-disciplinary open access archive for the deposit and dissemination of scientific research documents, whether they are published or not. The documents may come from teaching and research institutions in France or abroad, or from public or private research centers.
L'archive ouverte pluridisciplinaire HAL, est destinée au dépôt et à la diffusion de documents scientifiques de niveau recherche, publiés ou non, émanant des établissements d'enseignement et de recherche français ou étrangers, des laboratoires publics ou privés.

\section{(c)(1)}

Distributed under a Creative Commons Attribution| 4.0 International License 


\title{
Effects of temperature on the mechanical behavior of filled and unfilled silicone rubbers
}

\author{
T. Rey ${ }^{1}$, G. Chagnon ${ }^{1}$, J.B. Le Cam $^{2} \&$ D. Favier ${ }^{1}$ \\ ${ }^{1}$ Université de Grenoble/CNRS, Laboratoire 3SR, domaine universitaire, 38041 Grenoble Cedex 9, France. \\ ${ }^{2}$ Université de Rennes 1, L.A.R.M.A.U.R. - CNRS 6274, Campus de Beaulieu, Bât. 10B, 35042 Rennes Cedex, \\ France.
}

\begin{abstract}
In this contribution, the influence of the temperature on the mechanical behavior of a filled and an unfilled silicone rubber was analyzed. Firstly, the crystallization and melting temperatures were determined by differential scanning calorimetry. Secondly, mechanical tests were carried out at different temperatures above that of crystallization, up to $150^{\circ} \mathrm{C}$. Results show that both silicone rubbers exhibit an entropic behavior in this temperature range. Thirdly, the temperature influence on the stress softening and mechanical hysteresis is studied and analyzed.
\end{abstract}

\section{INTRODUCTION}

The easiness of cure and manufacture of silicone rubbers explains their increasing use in many applications.

Classically, silicone rubbers are filled to increase their stiffness. In this case, the mechanical response is complicated, exhibiting numerous phenomena, as non-exhaustively stress softening (Mullins, 1948), Payne effect (Payne, 1962) and mechanical hysteresis. The mechanical response of filled and unfilled silicone rubbers has already been characterized in the literature at room temperature (Meunier et al., 2008, Machado et al., 2010, 2012), but no study investigates the effects of temperature on the mechanical response, while the large variety of applications requires a large temperature range of use. Moreover, the fillers and rubber matrix interactions are affected by the temperature variation (Rothon, 2001), so it is necessary to study both the filled and the unfilled silicone rubbers.

This paper investigates so the temperature influence (above that of crystallization) on hyperelasticity, stress softening and mechanical hysteresis. The materials and experimental setup are given in Section 2. Section 3 gives the results obtained for both materials. The evolution of the various phenomena involved in the deformation of silicone rubbers is discussed in Section 4. Finally, concluding remarks close the paper.

\section{EXPERIMENTAL SETUP}

\subsection{Elaboration of the silicone rubbers}

A similar elaboration process is used for the two materials. Firstly, the uncured unfilled silicone RTV 141A (or RTV 3428A for the filled silicone) and $10 / 1 \mathrm{phr}$ in weight of the curing agent RTV 141B for the unfilled silicone (or RTV $3428 \mathrm{~B}$ for the filled silicone) are blended, and then degassed for 30 minutes in a vacuum chamber. The degassed liquid is injected by the way of a medical syringe in a closed mold to guarantee a constant thickness (2 $\mathrm{mm}$ ) of the specimen. Finally, the material is cured by putting the mold in an oven at a temperature of $70^{\circ} \mathrm{C}$ during 4 hours.

A second heating at $150^{\circ} \mathrm{C}$ during 3 hours is performed on the unfilled silicone as it was not fully cross-linked with the classical previous preparation. More details about the cross-linking checks are presented in Rey et al. (2013). 


\subsection{DSC analysis}

In order to define the crystallization and melting temperatures of the two silicones, DSC (Differential Scanning Calorimetry) tests are carried out.

A TA Q200 differential scanning calorimeter is used to perform the DSC. A cooling is performed in a temperature range between $0{ }^{\circ} \mathrm{C}$ and $-90^{\circ} \mathrm{C}$, and then the heating is carried out in the same temperature range. The cooling and heating rates are set to $2^{\circ} \mathrm{C}$ per minute. Specimens of 29 and $37 \mathrm{mg}$ weight are used for the unfilled and filled silicones, respectively.

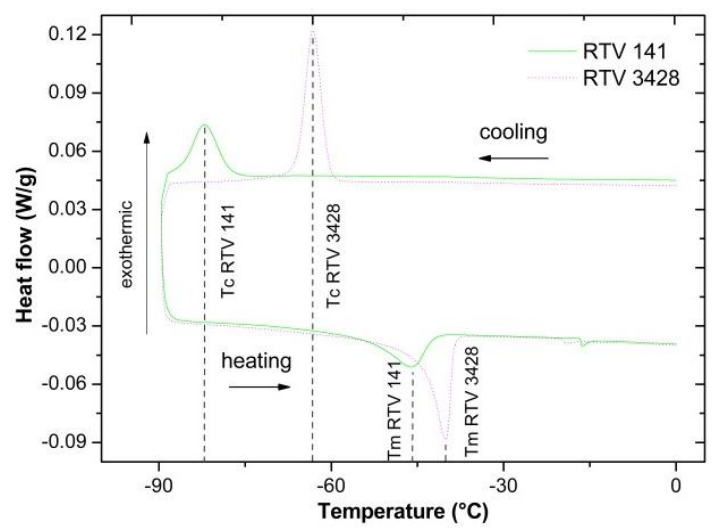

Figure 1. Results of the DSC tests.

Figure 1 presents the results of the DSC. An exothermal and an endothermal peak in the heat flowtemperature curves are observed for the two materials during cooling and heating respectively, corresponding to the crystallization of some of the polymer chains for the exothermal peaks and to the crystallites melting for the endothermal peaks. These temperatures are denoted respectively $T_{c}$ and $T_{m}$ in the following, and their values are reported in table 1. These tests do not allow to determine glass transition temperatures for both materials, which occur at temperature lower than $-90^{\circ} \mathrm{C}$. DTMA analyses confirming these results are presented in Rey et al. (2013).

\begin{tabular}{|c|c|c|}
\hline Silicone & $\begin{array}{c}\text { Crystallization } \\
\text { temperature }\end{array}$ & $\begin{array}{c}\text { Melting } \\
\text { temperature }\end{array}$ \\
\hline Unfilled & $-83^{\circ} \mathrm{C}$ & $-47^{\circ} \mathrm{C}$ \\
\hline Filled & $-66^{\circ} \mathrm{C}$ & $-41^{\circ} \mathrm{C}$ \\
\hline
\end{tabular}

Table 1. Characteristic temperatures for the two silicone rubbers.

\subsection{Mechanical tests}

The RTV 3428 exhibits stress-softening, mechanical hysteresis and undergoes larger deformations (Machado et al., 2010, 2012) whereas the RTV 141 behavior is purely hyperelastic at room temperature, with a stretch at failure close to 2 (Meunier et al., 2008).
Due to these differences, the mechanical tests performed on both materials are different: for RTV 3428 , it is necessary to perform several mechanical cycles at increasing deformation. The mechanical cycles are carried out from 2.25 to 3.5 stretch level, with an increase of 1.25 stretch between each cycle. These tests are performed with a strain rate equal to $1.67 \mathrm{~s}^{-1}$, between $-40^{\circ} \mathrm{C}$ and $150^{\circ} \mathrm{C}\left(-60^{\circ} \mathrm{C}\right.$ is close to $\mathrm{T}_{\mathrm{c}}$ for this material). For RTV 141, only one uniaxial load-unload cycle at a stretch of 1.5 is performed, with a strain rate of $1.67 \mathrm{~s}^{-1}$, at temperatures between $-60^{\circ} \mathrm{C}$ and $150^{\circ} \mathrm{C}$.

\section{TESTS RESULTS}

The results obtained for the filled silicone are presented in figure 2. First, a significant difference between the load and unload curves is observed, which forms a hysteresis loop. Moreover, a difference of stiffness is observed between the first and

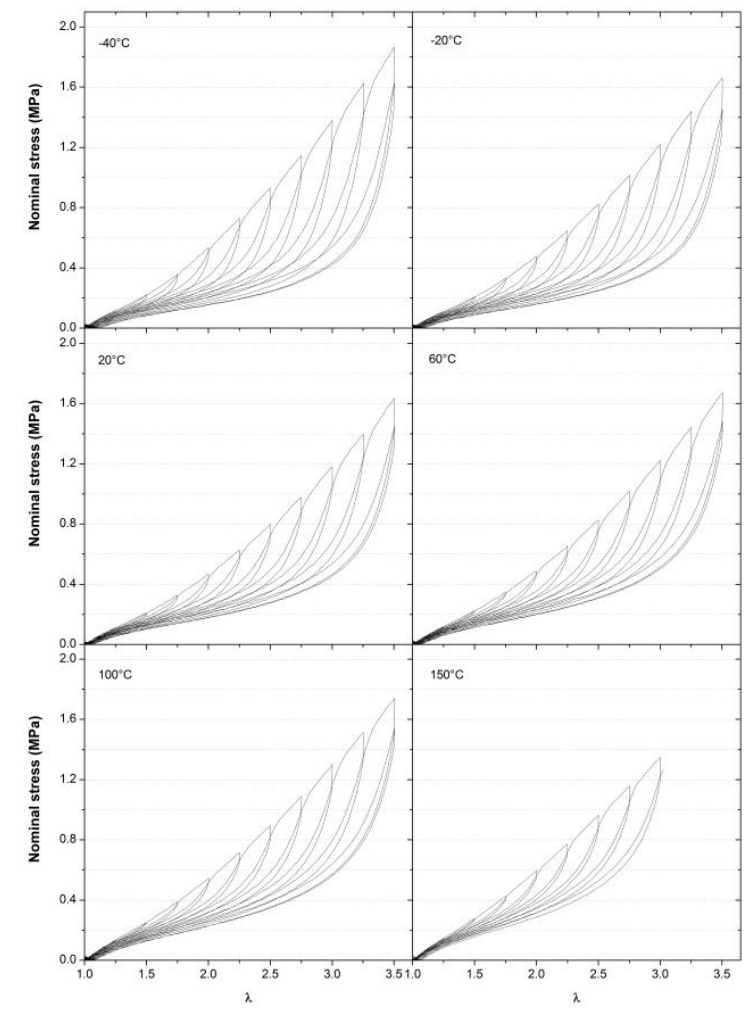

Figure 2. Cyclic strain-stress tensile test of the filled silicone rubber at different temperatures.

the second loads at a same stretch level. This softening is one of the features of the Mullins effect (Mullins, 1948). Second, for temperatures inferior to $0^{\circ} \mathrm{C}$, the material becomes stiffer when the temperature is close to $\mathrm{T}_{\mathrm{c}}$. For temperatures greater than $0^{\circ} \mathrm{C}$, despite a loss of material stiffness due to increasing viscosity with increasing temperature, the material becomes stiffer when the temperature increases, meaning that the entropic effect is more significant than the viscous one. It is to note that the test per- 
formed at $150^{\circ} \mathrm{C}$ is not complete as the specimen fails at about a stretch of 3 .

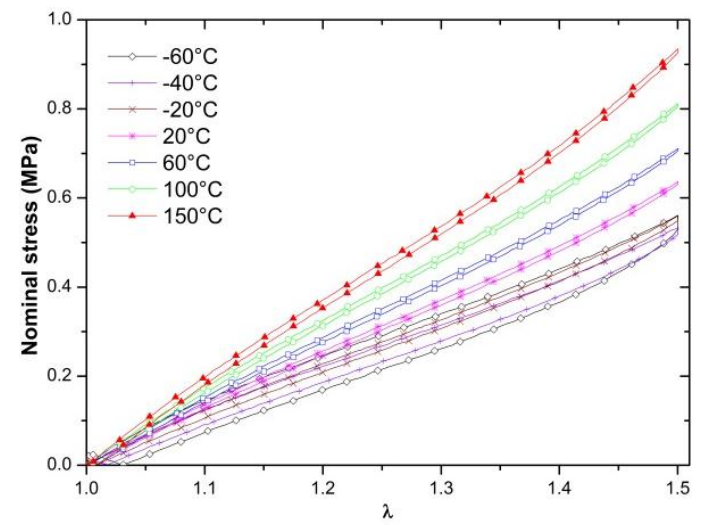

Figure 3. Tensile strain-stress curves at different temperatures for the unfilled silicone rubber.

Figure 3 presents the results of uniaxial tensile tests for the unfilled silicone. Except for a temperature equal to $-60^{\circ} \mathrm{C}$, the stiffness of the material increases with increasing temperature. These curves highlight the entropic behavior of the unfilled silicone rubber for temperature far from $\mathrm{T}_{\mathrm{c}}$. For temperature close to $\mathrm{T}_{\mathrm{c}}$, typically $-60^{\circ} \mathrm{C}$, the material behavior remains entropic, but crystallites form in the bulk material and act as fillers (Trabelsi et al., 2003, Flory et al.,1947). Consequently, the material stiffness increases, meaning that the effect of the crystallization on the mechanical response of the material is of the first order compared to that of entropy variation. It should be noted that the change in the elaboration process, more especially the fact that the material is fully cross-linked in the present study, explains the differences with the results obtained in Meunier et al. (2008).

\section{DISCUSSION}

\subsection{Mullins effect}

The unfilled silicone is not subjected to stress softening, this is the reason why this analysis only deals with the filled silicone. As classically observed in the literature, our results show that the filled silicone exhibits a stress softening that is mainly observed between the first and second loads (Machado et al., 2010). It has often been considered as a damage phenomenon (Beatty and Krishnaswamy, 2000, Chagnon et al., 2004, Diani et al., 2006).

In order to evaluate the stress-softening, several methods can be used, among them that by Stevenson et al. (2001). This method consists in calculating the ratio between the energies brought during load and unload. In the present study, we calculate the ratio between the energies brought during second (W2L) and first (W1L) loads. This method, which was previously proposed in (Machado et al., 2010), allows to remove the effect of hysteresis on the calculation. The measurement of energy is defined by:

$$
W=\int_{\overline{\bar{F}}} \overline{\bar{\pi}}: d \overline{\bar{F}}
$$

where $\overline{\bar{\pi}}$ is the nominal stress tensor and $\overline{\bar{F}}$ is the deformation gradient tensor.

Figure 4 presents the evolution of this ratio for different maximum stretch levels from 1.25 to 3.5 for a temperature range between $-40^{\circ} \mathrm{C}$ and $150^{\circ} \mathrm{C}$. It appears that the energy loss increases with deformation whatever the temperature is. The curves corresponding to 60,100 and $150^{\circ} \mathrm{C}$ are confounded, meaning that above $60^{\circ} \mathrm{C}$, the stress softening evolution is not enough dependent on the temperature, whereas below $60^{\circ} \mathrm{C}$, the lower the temperature, the higher the stress-softening. This means that the macromolecular network is more sensitive to stress softening for low temperatures.

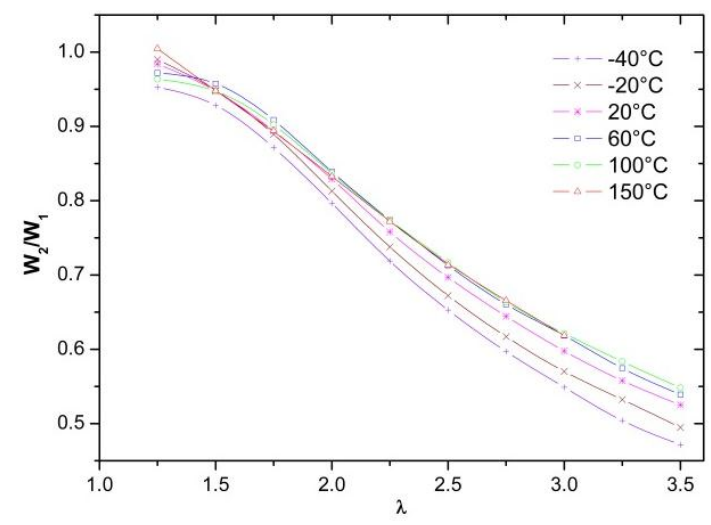

Figure 4. Energy ratio evolution between first and second loads versus the maximum elongation for different temperatures.

\subsection{Mechanical hysteresis}

For the filled silicone rubber, the hysteresis loop is observed for stretch from 1.25 to 3.5. Figure 5 presents the hysteresis between the second load and unload (W2L-W1U) versus the stretch. The hysteresis is observed during the second loads as during the first ones the hysteresis can be confounded with the

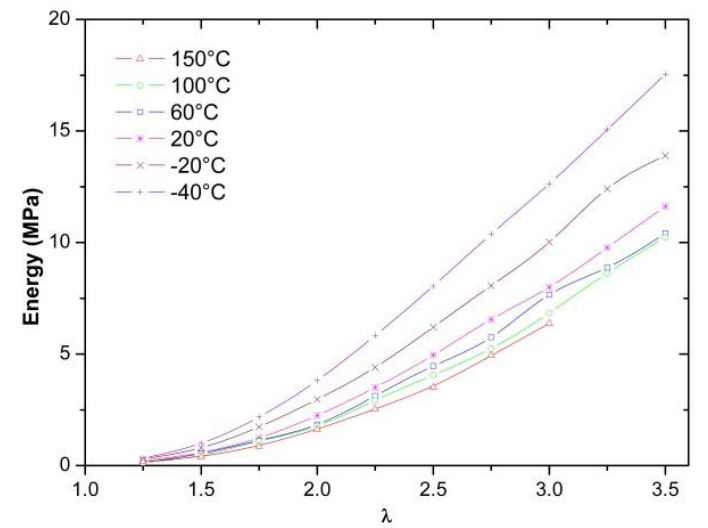

Figure 5. Energy corresponding to the hysteresis during the second cycle for the filled silicone at different temperatures. 
Mullins effect, see Rey et al. (2013) for more details about this phenomenon. As shown in this figure, the hysteresis loop area increases with the stretch. It can be observed that the higher the temperature, the lower the hysteresis loop area.

In unfilled silicone, mechanical hysteresis is only observed for a maximum stretch reached equal to 1.5. For smaller stretch levels, it is not detected. Figure 6 gives the evolution of the hysteresis area between load W1L and unload W1U (W1L-W1U) versus the temperature for this maximum stretch level. As shown in this figure, the hysteresis loop area is quasi-constant for temperatures above $0^{\circ} \mathrm{C}$. However, for temperatures below $0^{\circ} \mathrm{C}$, the hysteresis loop area highly increases until the temperature reaches $\mathrm{T}_{\mathrm{c}}$.

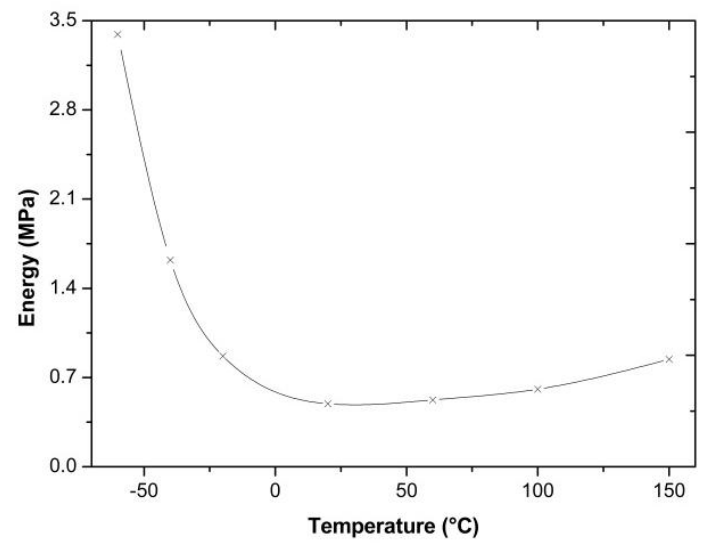

Figure 6. Energy corresponding to the loop of hysteresis for the unfilled silicone for a strain of $50 \%$ at different temperatures.

\section{CONCLUSION}

This study investigated the effects of temperature on the mechanical properties of filled and unfilled silicone rubbers, especially on hyperelasticity, mechanical hysteresis and stress softening. Results show that the stabilized behavior of silicone rubbers depends quasi-linearly on the temperature. This is not true for the other phenomena. Typically in filled silicone rubber, the magnitudes of hysteresis and stress softening decrease with increasing temperature. Moreover, up to $60^{\circ} \mathrm{C}$, the temperature does not alter any more the stress softening. For these reasons, the modeling of phenomena involved in the deformation of rubbers should account for the nonlinear dependence of these phenomena on the temperature. Consequently, this study opens a new way in the modeling of classical phenomena observed in rubbers, more particularly in the modeling of the Mullins effect, whose softening function should depend on a decreasing and asymptotic function of the temperature. Further work in this field is currently carried out by the authors.

\section{ACKNOWLEDGEMENTS}

This work is supported by the French National Research Agency Program n²010BLAN90201 ANiM ("Architectured NiTi Materials").

\section{REFERENCES:}

Beatty, M. F. \& Krishnaswamy, S. A theory of stress-softening in incompressible isotropic materials. J. Mech. Phys. Solids 2000; 48: 1931-1965.

Chagnon, G. \& Verron, E. \& Gornet, L. \& Marckmann, G. \& Charrier, P. On the relevance of Continuum Damage Mechanics as applied to the Mullins effect in elastomers. J. Mech. Phys. Solids 2004; 52: 1627-1650.

Diani, J. \& Brieu, M. \& Gilormini, P. Observation and modeling of the anisotropic visco-hyperelastic behavior of a rubberlike material. Int. J. Solids Struct. 2006; 43: 3044-3056.

Flory, P.J. Thermodynamics of crystallization in high polymers. I. Crystallization induced by stretching. J. Chem. Phys. 1947; 15: 397-408.

Machado, G. \& Chagnon, G. \& Favier, D. Analysis of the isotropic models of the Mullins effect based on filled silicone rubber experimental results. Mech. Mater. 2010; 42: 841-851.

Machado, G. \& Chagnon, G. \& Favier, D. Induced anisotropy by the Mullins effect in filled silicone rubber. Mech. Mater. 2012; 50: 70-80.

Meunier, L. \& Chagnon, G. \& Favier, D. \& Orgéas, L. \& Vacher, P. Mechanical experimental characterisation and numerical modelling of an unfilled silicone rubber. Polym. Test. 2008; 27: 765777.

Mullins, L. Effect of stretching on the properties of rubber. Rubber Chem. Technol. 1948; 21: 281300.

Payne, A.R. The dynamic properties of carbon black-loaded natural rubber vulcanizates. Part I. $J$. Appl. Polym. Sci. 1962; 6: 57-63.

Rey, T. \& Chagnon, G. \& Le Cam, J.-B. \& Favier, D. Influence of the temperature on the mechanical behavior of filled and unfilled silicone rubbers. Polym. Test. 2013; 32: 492-501.

Rothon, R. N. Particulate Fillers for Polymers. In Smithers Rapra Technology. UK, 2001.

Stevenson, I. \& David, L. \& Gauthier, C. \& Arambourg, L. \& Davenas, J. \& Vigier, G.. Influence of $\mathrm{SiO}_{2}$ fillers on the irradiation ageing of silicone rubbers. Polymer 2001; 42: 9287-9292.

Trabelsi, S. \& Albouy, P.A. \& Rault, J.. Crystallization and melting processes in vulcanized stretched natural rubber. Macromolecules. 2003; 36: 76247639. 